\title{
Innovation Analysis of University Humane Spirit and Moral Education
}

\author{
Fan Zhu \\ School of Sccels, Wuhan University of Technology, Wuhan 430070, China. \\ hgzf@whut.edu.cn
}

\begin{abstract}
University humane spirit is the core and soul of university education, and also an important reflection of moral development in students group. This article is based on humane spirit, then the discussion and analysis are organized with the following six key points: stimulating university students' psychological recognition and inherent demand of moral education; changing the traditional moral concept of " The teacher is the only principal part of moral education ", meanwhile accepting and respecting the main status of students among moral; promoting moral educators' own professional accomplishment and humane inside information; riching the humane connotation of moral education content; deepening ethic education by experience; strengthening the construction of humanistic moral education environment. It can provide support for innovating ways and enhancing effectiveness of university moral education work.
\end{abstract}

Keywords: University; humane spirit; moral education; innovation.

\section{大学人文精神与大学德育工作创新探析}

\section{朱凡 \\ 化学化工与生命科学学院, 武汉理工大学, 武汉 中国}

摘 要: 大学人文精神是大学教育的核心, 是大学教育的灵魂所在, 是大学生群体道德发展的 重要体现。本文基于大学人文精神, 围绕激发大学生德育的心理认同和内在需求、转变“教 师是德育唯一主体” 的传统德育观念, 认可并尊重学生在德育中的主体地位、提升德育工作 者自身的专业素养和人文底蕴、丰富德育内容的人文内涵、深化体验式德育教育、加强德育 人文环境的建设六个方面进行探析, 为创新大学德育工作途径, 增强大学德育工作实效性提 供支撑。

关键词: 大学; 人文精神; 德育; 创新

\section{1. 人文精神的起源与内涵}

人文精神是一个古老而常新的话题。从词源上来看, “人文精神” 源于拉丁文Humane studio, 即人的研究之意, 英文为Humanity, 是相对于神的研究而言的。从文化的角度来看, 人文精神是指人类通过实践活动, 在构建各种制度、规范与生成物质产品过程中所形成的观 念、风俗、生活方式和社会心理, 包含维持人类正常生活的价值追求、伦理观念、群体意识、 生命激情、生活方式和思维方式，也包括推动人类社会发展的反省意识、远大理想、民族精 神以及政治信仰 ${ }^{[1]}$ 。纵观人类历史和东西方文化, 人文精神在起源和发展演化的历史长河中 始终都和教育相生相伴。从柏拉图主张的 “哲人治国” 到纽曼倡导的 “博雅教育”，从我国 《易经》的 “观乎人文, 以化天下”, 到《大学》的 “大学之道, 在明明德, 在亲民, 在止 于至善”，无不都是围绕着人文精神。

从本质上说, 大学人文精神与一般人文精神并无区别。即倡导整体的人学观, 以人为本、 尊重个性的价值观, 对他人、社会、国家、自然的人文情怀及和谐共生观, 独立自由追求真 理的社会批判精神以及社会责任与永恒道德精神 ${ }^{[2]}$ 。 


\section{2. 基于人文精神谈大学德育工作的创新}

哈佛大学前校长德鲁克・博克指出 “在今天, 如此众多的大学生还持有相对主义的观点, 缺乏思考复杂问题, 无论是道德问题还是其他问题的能力。” 美国教育家德怀特 - 艾伦说:

“如果我们使学生变得聪明而未使他们具备道德性的话, 那么我们就在为社会创造危害。” 大学时期是大学生世界观、人生观、价值观形成的关键时期, 是大学生品性、道德发展的重 要阶段。加强大学生政治教育、思想教育、品德教育等德育工作，大学任重道远。基于人文 精神, 传承和创造人类文化, 塑造学生的思想和灵魂, 指引学生求知明理、关怀终极价值、 传承人类文明、提升人类精神、守护人类尊严, 是大学德育工作的核心内容和要实现的终极 目标。

2.1. 唤起大学生对德育的心理认同和接受德育熏陶的内在需求

理论上讲，对于道德教育之于社会教化的功能和作用的认同，本身并不存在任何问题。 但在现实中, 道德教育却由于种种原因远离了人们的生活, 被人们所怀疑。“做人要诚实吗?” 这个看似简单的问题, 当在大学思想道德修养课堂上被提出来时, 却产生了不同的答案。有 的学生回答 “看情况”、有的学生回答 “做人不能太诚实”。类似现象在某种意义上，我们 可以概括为社会成员对现行道德教育的认同危机。受当前多元文化冲击的影响，大学生的价 值观也呈现出多元化。培养和具备高尚的道德情操，坚持遵守既定的社会准则，已不再被大 学生一致认同和重视, 逐渐被边缘化, 变成了一种 “说起来重要, 做起来次要, 忙起来不要” 的可有可无的教育。在现代社会, 在这个选择多样化的时代, 真理可能与学生价值无涉, 知 与信、知与行并不必然相关。因此, 大学德育工作者只有以学生为本, 切入学生的所思所想, 点燃学生思维, 唤起学生对德育的心理认同和自主接受德育熏陶的内在需求和内在动机, 大 学德育工作才能吸引学生, 赢得学生, 才有需求, 有效果。

2. 2. 尊重学生在德育中的主体性, 转 “占有式” 德育为“共生式” 德育

千百年来教师与学生之间的教学地位和教学关系一直是教育与被教育、上对下的关系。 传统的德育工作, 也十分强调教师的作用, 把教师看作是德育工作的唯一主体, 把学生看作 是接受德育熏陶的客体, 是一种 “占有式” 德育, 遵从的是 “主体一客体”二分式的思维范式。 在这种思维范式中的教育者习惯以一种对待物的方式来教育人, 把德育对象视为没有自主性、 冷冰冰的物, 势必会导致在德育实践中把学生置于客体被改造的位置, 学生个体由于目的地 位的丧失而论为 “物” 的存在和 “工具” 的存在，德育理论和实践则陷入 “物化” 的䢟尤境 地。创新大学德育应转换传统观念, 重视学生的主体性和主动性, 把学生既看作是德育的客 体，同时也看作是自我教育的主体，把教育者和受教育者都看作是一种主体性存在，遵从“共 生式” 的 “主体一主体” 的思维范式, 维护教育者和受教育者之间的 “共生” 和 “共享” 关系。

2.3. 提升德育工作者自身的专业素养和人文底蕴

当代大学生思想日趋开放、活跃、可塑性大，但同时又缺乏独立思考复杂问题、独立甄 别是非的能力和自主选择的能力, 大学德育面临着比过去任何时候都要困难得多的挑战, 能 否实现 “共生式” 课堂教学转向, 在很大程度上取决于德育工作者自身素质的高低和文化底 蕴的深浅。目前, 大学德育工作者群体主要包括思想政治理论课学者、教师、辅导员、班主 任，这其中很大一部分人都存在着社会阅历简单，德育理论基础弱，知识结构单一，人文底 蕴贫乏等问题, 很容易造成德育工作者思想僵化, 语言单调乏味, 教育方法简单甚至粗暴。 这不但无法达到德育的效果, 反而引起学生的逆反心理, 适得其反。因此大学德育工作者需 不断学习掌握最新的思想政治教育理论成果, 提高自身的理论素养; 不断提高自身的人格素 养, 使自己具备高度的敬业精神和高尚的人格魅力; 不断学习研究新理论、新问题, 优化自 身思想政治教育知识结构; 更重要的是，需要提升自己对思想政治教育理论的忠诚度，即对 这些理论有发自内心的、真正的相信和忠诚。我们无法想象一个对自己所传授的理论都不相 信、不自信的人能够通过教育让学生信服。在德育实践中, 德育工作者还应树立以人文本的 人文主义学生观, 尊重学生的主体地位, 尊重学生的个性, 要能给学生提供多样化、多元化 的道德情境和道德问题, 启迪他们对道德本质的终极探究和思索。摒弃传统的德育教化观, 
倡导师生平等对话意识, 树立德育 “人化观” 深化自己对大学人文精神的认知, 人化学生首 先要人化自己, 缺乏人文精神和意识的教师是不可能培养出具备良好的道德素养的学生的。

2.4. 丰富德育内容的人文内涵

受过去计划经济的影响以及对市场适应性的过度关注, 过分细化的专业教育使得大学教 育呈现科学和人文分离的态势。在开展教育活动中, 技能性, 实用性的专业知识更受学生推 崇, 教育趋势呈现实用主义, 功利主义, 专业掩盖了文化, 知识遮蔽了人性, 整个教育内容 重实证性, 轻人文性, 缺乏鲜活的人文精神。大学变成了培养专门技能人才的职业培训机构, 这样培养出的学生是片面的, 是不完整的, 有违大学人文精神。大学德育应通过传承和创造 优良传统文化, 在德育理论教育和实践教育中融入艺术, 文学, 哲学等人文元素, 丰富德育 内容的人文内涵。同时, 还应以学生为本, 以学生正常生活实际出发, 坚持贴近实际, 贴近 生活, 贴近学生的原则, 推动德育内容生活化, 避免 “假、大、空” 的单一理论灌输, 尝试 在日常生活中阐释其道德教育意义, 释放其之于生活世界的引领作用。

2.5. 注重德育体验, 知行合一

《朱子语类》上说 “讲论自是讲论, 须是将来自体验。体验是自心理暗自讲量一次。”刘 惊铎也提出 “体验” 是人类的基本生存方式之一, 是一种图景思维活动, 也是一种震撼心灵、 感动生命的鬼力化育模式 ${ }^{[3]}$ 。大学德育仅靠教师在课堂上讲道理, 谈意义是远远不够的, 须 靠学生自己去认同、追求和亲身体验, 通过不断地学习体验, 获得更深刻的认知和反思, 将 道德准则转变成自己的个人信念, 内化为自己的精神财富。21世纪初, 朱小蔓教授提出 “生 命叙事” 理论, 通过叙事与个体生命、生活经历相结合, 挖掘出更深刻的生命、生活哲理, 探索人的生命存在意义, 得出新的人生感悟。此教育理论在大学德育中已有所体现, 如杰出 青年学子事迹报告会、支教团先进事迹巡讲、红军后代讲家风等活动都是基于 “生命叙事” 理论的情感体验教育。这种德育途径取得了一定的育人效果, 但又衍生出了拉票推典型、分 指标凑人数强迫听报告等严重违背德育理念, 违背大学人文精神的问题, 让德育情感体验教 育效果大打折扣甚至适得其反。大学德育工作者应足够重视德育情感体验教育, 坚持以人为 本, 以德为先, 尊重学生个体主体性, 赋予学生树典型、学典型的主动权和自主权, 让德育 情感教育更具实效。其次, 大学还可尝试角色换位体验、游戏活动体验、实地调查体验、行 为训练体验等行为体验法实施德育, 让学生在体验中多想、多参与、多思考、多感悟。

2. 6. 注重环境育人，浓郁德育环境的人文氛围

传统的大学德育环境建设主要是指在校园硬件设施和校园文化活动的建设, 这两个方面 对学生品德发展的确至关重要, 但对于有较高层次自我实现需求、有开放性思维和一定的自 觉性的大学生来说, 对大学德育环境的追求应该有着更高的价值标杆。大学的办学理念、精 神文化、大学学者的道德风范、行为方式、大学的学术道德操守、创新人才的培养机制、学 术自由等才是体现大学人文精神的重要环境因素, 是一种不教之教的隐形教育, 应成为大学 德育环境建设的重中之重。随着信息技术的飞速发展, 网络如同一只无形的手, 已成为影响 大学生道德发展和价值观念形成的重要推动力量, 它在带给大学生更丰富、更全面的资讯和 大学生学习方式重大变革的同时, 也带来了多元文化和多元价值观的冲击, 导致大学生精神 倦急、逆反心理、价值观混淆、人生观迷茫、成功观扭曲等问题。净化网络环境, 开辟德育 网络阵地, 让大学的网络文化饱含大学人文精神也是大学德育环境建设的重要课题。

\section{3. 结语}

人文精神是大学教育的核心和灵魂所在, 是大学生价值观念形成、德性品行发展的重要 体现。大学德育工作应基于大学人文精神, 坚持以学生为本, 从大学生对德育的观念认同和 内在需求出发, 转变 “教师是德育唯一主体” 的传统德育观念, 认可并尊重学生在德育中的 主体地位, 提升德育工作者自身的专业素养和人文底蕴, 丰富德育内容的人文内涵、注重德 育体验式教育, 引导学生知行合一, 强化德育人文环境的建设, 增强大学德育工作的实效性。 


\section{References}

[1]. Defeng Chu. Reflection and Beyond: Multidimensional perspective of Moral Education in Universities under the Credit System. Shanghai Academy of Social Sciences Publishing House, 2014.

[2]. Yongzhong, Huang.Innovation Analysis of University Humane Spirit and Moral Education. The Party Building And Ideological Education In Schools. Vol. 4 (2012) No. 11, p.87-88.

[3]. JingDuo Liu.Research On Moral Experience. People's education Press,2003 